\title{
Capítulo VI \\ Colombia: entre el fetiche de la democracia y el neuroliberalismo
}

ntes de comenzar este capítulo, es necesario que el lector lo-
gre digerir la siguiente frase de un gran autor esloveno: "el principal problema político de hoy en día es: ¿cómo rompemos este consenso cínico? La democracia formal en sí misma no debe ser fetichizada (Žižek, 2000, p. 10).

En este capítulo quiero exponer tres apartes: el primero, que en Colombia nos acoge una paradoja social y política en la medida en que poseemos grandes posibilidades de conocer a profundidad los diferentes fenómenos problémicos que existen, pero a la vez, existe una característica contemporánea que consiste en la dificultad de materializar las soluciones a dichos fenómenos. Dicha paradoja conlleva a un problema fundamental a la hora de hablar de política que resumo en una pregunta que he escuchado: ¿y de qué sirve comprender el estado de la situación en nuestro país si total nada va a cambiar? La respuesta a este interrogante la plasmaré implícita en el desglose de este primer aparte.

El segundo, que mientras no realicemos una crítica constructiva o mejor, destructiva, contra ese fetichismo discursivo que instaura a la democracia como una forma lingüística indiscutible pero que niega u oculta tantos rasgos de fracaso y errores prácticos, es probable que aquella pregunta con la que estudiantes y docentes 
preocupados por la realidad del país siempre tienen, ese ¿y qué podemos hacer? jamás se resuelva coherentemente, ya que sentarnos a pensar qué podemos hacer, es consecuentemente sentarnos a hablar sobre política y sentarse a hablar sobre política en Colombia también encierra la posibilidad de preguntarnos ¿en verdad Colombia necesita la democracia? ¿Podríamos pensar en otro tipo de modelo político para organizarnos? ¿Es en verdad una democracia el modelo político que tiene hoy Colombia? Si usted como lector ya tiene una respuesta a las preguntas que acabo de plantear en el marco de este penúltimo capítulo, yo hago una plegaria para que se tome el tiempo de pensar su respuesta mucho mejor.

Y el tercer aparte, plantear que en Colombia se ha instaurado el "neuroliberalismo" como una opción eficaz para que un individuo nunca se constituya en un sujeto crítico y, por consiguiente, mucho menos en un sujeto político. $\mathrm{Al}$ respecto de este tercer aparte, considero que la instauración del neuroliberalismo como un modus operandi mental para mantener al individuo lejos de la realidad política es el motor de la negación al diálogo sobre política, en otras palabras, el neuroliberalismo sería el responsable de que la gente siga opinando como un lugar común muy conocido en Colombia que "la política es una mierda".

Antes de comenzar el desglose de los tres temas que presento en este capítulo, no quiero que el lector se inquiete por el concepto "crítica destructiva"; lo menciono, porque en una ocasión de un congreso nacional sobre temas sociales, tuve líos de baja intensidad con una docente que me insistió en no utilizar la palabra "degradación". En aquella ocasión, expliqué dicha palabra para exponer la transformación de los elementos propios de la oligarquía en nuevos elementos característicos de una tecnocracia clientelista. Para mí, existe una degradación (en el sentido más literal de la palabra), cuando concluyo que el poder en Colombia ya no lo tiene la oligarquía, sino una tecnocracia clientelista, se pasó de algo muy malo para una democracia a algo peor y eso es degradación. 
Empero, aunque no es el espacio para explicar dicha coyuntura, menciono la anécdota, porque vale la pena recalcar que la academia no debe temer a usar ningún concepto siempre y cuando exista una argumentación. Ese miedo, ese escollo, esa servidumbre a la retórica que muchos manejan en los niveles académicos, a veces no provoca ni aceptación ni rechazo, iy eso sí que es un problema cuando uno habla de política! ya que lo más valioso de un diálogo, de una ponencia, de ideas que son habladas o escritas, es generar un acuerdo o un desacuerdo que edifique el diálogo y lo guíe hacia una conclusión o inclusive si el desacuerdo es sumamente valioso, hacia la constitución de corrientes diversas.

De acuerdo con lo anterior, considero que, por una parte, la crítica constructiva es el emblema de una academia seria, que atiende, lee, comprende y formula alternativas analíticas. Por otra parte, la crítica destructiva, sería el emblema de una postura académica que comprende racional y éticamente la magnitud de una contradicción e intuye coherentemente, luego de un análisis, que hay cosas, como por ejemplo, el fetichismo democrático, que es mejor destruirlas, no so pretexto de un capricho tonto, sino más bien con el fin de edificar una propuesta mejor, y evitarnos tan siquiera el intento de reconfigurar lo que definitivamente no sirve socialmente hablando.

Por eso, considero que la crítica destructiva, constituye también una actitud académica y ante todo ética, pues muchas veces como estudiantes, esperamos no solo la mención de los problemas, sino andamos siempre atentos a la posición ética de quien los expone, en este caso el docente. Es decir, que la materialización de la posición ética de quien menciona un problema es una posición que vincula eficientemente presupuestos para la acción, contra aquello que se denuncia como resultado de un análisis crítico. En palabras más simples, si un estudiante pregunta preocupado, ¿qué podemos hacer?, la peor respuesta de un docente sería decir "no sé"; supongo que un "no sé" podría derivar en desinterés, 
indiferencia o frustración por parte de quien pidió una respuesta o incluso, dejar preparado el escenario para tildar de ingenuidad académica el ejercicio de comprensión crítica, porque total, ¿para qué? Realizada la mención, comencemos entonces con el primer aparte: la paradoja social y política.

No hay que tener miedo de las paradojas. Soy muy franco a este respecto, cuando la gente me pregunta: “¿Qué debemos hacer?”, respondo que no lo sé. Es mucho más modesto lo que trato de hacer, se trata solo de subrayar que los antagonismos, por utilizar este término rimbombante, del actual sistema global, antagonismos económicos, éticos, culturales, no podrán ser resueltos en el seno del sistema mismo. Creo que esto es lo único que podemos hacer en la época que Fukuyama ha calificado de "final de la historia", subrayar esos antagonismos. (Žižek, 2000, p. 5)

Para comenzar a explicar el tema de una paradoja social y política, la anterior cita, pueda ser un anclaje para abordar la cuestión. Ese "no lo sé" de Žižek es precisamente la resolución de que no hay paradoja en cuanto a la acción política se refiere.

Primero, existe la creencia de que la solución de los problemas políticos es imposible de acoger, segundo (y correlativamente) que no sirve de nada saber en qué consisten los problemas, si al final todo seguirá igual y nada cambiará. Si he sido claro, tanto la primera como la segunda apreciación, son en esencia lo mismo, son un círculo vicioso en el que la gente que habla de política se puede ver inmersa. Hablamos, señalamos, criticamos, reconocemos los problemas políticos, pero las cosas no cambian.

La idea en sí, de que las cosas son complejas y que por ende no se transforman, es a lo que yo me refiero con la paradoja social y política. Un fenómeno que impulsa los discursos más pesimistas sobre el cambio social que he conocido, o bien, los discursos más degradantes sobre la política que sigo escuchando, ya no con palabras elaboradas y hasta fatalistas, sino como simples lugares comunes, que 
dejan el escenario del interés individual extremadamente dispuesto a cualquier otra cosa que no sea hablar sobre política.

Es una paradoja social, porque las ciudades son altamente densas en términos poblacionales; no obstante, lo social, es decir lo común, lo colectivo, lo de todos, se ha convertido en lo propio, lo mío. Por lo tanto, emerge la paradoja social cuando somos tantas personas, estamos tan juntas, pero a la vez tan separadas de la visión de conjunto.

Es una paradoja política, porque al régimen político colombiano se le ha llamado democracia estable desde hace mucho tiempo, también, para nadie es un secreto que tenemos por lo menos en el papel y en toda la estructura institucional, una democracia representativa. La contradicción emerge de la paradoja social, ¿cómo hacer fluir una democracia en una sociedad que pierde de vista lo social? ¿Cómo puede haber una democracia si a la gente no le interesa la política? Una cosa es democracia representativa, pero otra muy distinta es votar con una voluntad viciada por el marketing político y considerar que eso es política como tal; sin embargo, ¿es la paradoja social y política un fenómeno exterior al individuo, es un problema interior o tiene características ambivalentes?

Bien, la paradoja social y política no está afuera, la paradoja social y política, no es una contradicción tácita del resultado de pensar en los problemas y no saber cómo o por qué no cambian en nada. La paradoja no es un atributo de la política o del diálogo sobre la política. La paradoja social y política no se constituye a partir de la imposibilidad de un cambio de la situación política, sino que la paradoja está adentro, adentro de cada individuo, que ha preferido seguir viviendo la vida de pequeños goces y grandes opresiones, antes que arriesgar su propia integridad. Y esa compulsión a vivir pequeños goces con tal de soportar las grandes opresiones, contribuye sistemáticamente al fortalecimiento del mercado de consumo superfluo. 
Quiero orientar esta explicación a partir de una pregunta; ¿de dónde salía el valor de tanta gente que, en Colombia, en Latinoamérica, se lanzó "a ciegas" a una lucha política categorizada como un elemento escatológico más elevado que la vida misma? Ese no lo sé de Žižek es precisamente la falacia y consiguiente frustración que encuentra aquel que estudia las cuestiones políticas, que asiste a una cátedra sobre política esperando ahondar, profundizar, que dedica tiempo a comprender, que enarbola una crítica profunda, seria, académica, pero que al final, parece que se queda sin posibilidades de acción, de prácticas en el marco de una sociedad tan convulsionada, como por ejemplo, la sociedad colombiana.

¿Qué hacer entonces para superar esa paradoja que conlleva en su interior y es impulsada sistemáticamente, por cada individuo hoy en día? Mi repuesta rápida: ser sujetos políticos. Pero eso cuesta, en parte lo podría considerar un sacrificio. Por supuesto hablar de sacrificio en una vida contemporánea tan "sobreofertada" para sublimar placeres puede sonar hasta ridículo.

Tal vez por eso Žižek dice no saber, porque si dijera la respuesta, estaría implicada la muerte de su estilo de vida y la entrega a un aparente etéreo servicio colectivo: la acción política. Tal vez por eso, la propuesta de denuncia de poderes planteada en gran parte de la teoría de Foucault solo serviría para saber qué tan oprimidos estamos, pero no, hasta dónde o qué podríamos hacer para dejar de estarlo sin estar permanentemente pensando como neuróticos, que tal vez el poder nos persigue hasta en la forma en que nos sentamos en el inodoro. La caricaturización de lo anterior no es fomento al irrespeto, es el reconocimiento de que un "no sé" puede conducir a una frustración que bien puede ser ocultada con la rabia o, peor aún, con la indiferencia frente a la política.

Él era capaz de admitir racionalmente la muerte de su esposa, pero con el hámster bloqueaba la verdad contenida en su aceptación de esta muerte [...] como saben los hámsteres viven 
por muy poco tiempo: medio año después de la muerte del hámster, el tipo se quebró y debió ser hospitalizado por un intento de suicidio. Así es como creo que sobrevivimos hoy a la realidad capitalista, podemos ser muy realistas, actuar con crueldad, no tener ilusiones sobre la vida social, pero cuando encontramos a alguien que dice "no tengo ninguna ilusión, puedo aceptar la vida tal como es, cruel, sin ideales", háganle una simple pregunta: ¿Dónde está tu hámster? (Žižek, 2000, p. 4)

Preguntarse por el hámster que impulsa la paradoja es preguntarnos por el consumismo, por la mercantilización del lenguaje, de las prácticas sociales etc. Hasta este punto, creo que dejo abierta una pequeña línea de investigación que podría indagar sobre cómo una sociedad materializa su indiferencia política, cómo la gente hoy en día puede saber y ser consciente de que la realidad económica es cada vez más delimitada, más injusta, pero a la vez puede sentarse a pensar en qué más comprar o en cómo endeudarse más; es indagar cómo se puede ingresar a un restaurante, pedir un almuerzo, comer y observar en un noticiero las quimeras de una sociedad que vive feliz en medio de tanto desastre.

A propósito de lo anterior, vale la pena citar de nuevo al autor esloveno y dilucidar otro ejemplo, cuando se refiere a la crítica a una reciente tendencia occidental de asumir posturas y formas de ideologización del mundo oriental. ¿No ha escuchado que el fenómeno del yoga, la vida vegetariana, la comprensión energética y espiritual desde el punto de vista oriental se asume cada vez más en Colombia? Bueno, la pertinencia de la siguiente cita, prefiero que la juzgue el lector a propósito de lo que vengo exponiendo "mi idea es que este budismo occidental es un hámster gordo y grande. Puedes participar completamente en el salvaje juego capitalista mientras tu entrenamiento y tu meditación y demás, te dan la ilusión de que esa no es la vida real, solo estás jugando el juego social, en realidad estás en cualquier otro lado (Žižek, 2000, p. 5). 
Pasemos al segundo tema que quiero exponer en este capítulo: el fetichismo democrático. "En relación con la democracia, he de decir que no debemos ser tan fetichistas a la hora de utilizar el término "democracia", porque cualquier cuestionamiento de esta puede ser fácilmente considerado como antidemocrático" (Žižek, 2000, p. 6). Hoy, en Colombia, izquierda y derecha, altos y bajos, gordos y flacos, hombres y mujeres, ¡todos! ¡absolutamente todos! tienen ideas en ocasiones brillantes, pero a la hora de hablar de política, pareciera que no hay nadie que no hable de democracia, por la democracia, o con base en la democracia, como si "democracia" fuera una bola mágica que todos se rotan y hay que tomar en las manos para ejercer la palabra. Eso es fetichismo. ¿Acaso nadie puede al menos pensar que aquello que más nos ha traído problemas como país es precisamente una especie de régimen del fetichismo democrático? A propósito, dudar de esos paradigmas conceptuales todopoderosos debería constituirse en una forma inicial de la crítica. Por ejemplo, un gran autor como Liévano expresa una idea análoga con otros términos, partiendo de una crítica no a la democracia, pero sí al derecho:

El derecho ha sido la bandera favorita de la oligarquía colombiana porque la interpretación conservadora del mismo ha permitido que los de arriba confundan sus intereses con la juridicidad y los de abajo se vean en la alternativa de aceptar el precario lote que les fue asignado en el reparto de los beneficios de la nacionalidad o de convertirse, de lo contrario, en facciosos, enemigos de las instituciones y defensores de la arbitrariedad [...] fachada engañosa de la legalidad, mito del "legalismo", la filosofía de la libertadura. (Liévano, 2002, p. 678)

La libertadura a la que se refiere Liévano es, en otras palabras, creer que so pretexto de que las leyes son las leyes se deben respetar. ¡Qué gran falacia! ¡Qué fachada engañosa! Pues eso no significa otra cosa más que el asalto del Estado, cumplido periódicamente y 
a nombre de la libertad, del derecho, por una plutocracia insolente y reacia a permitir que el Gobierno sirva a intereses distintos a los suyos (Liévano, 2002). Bien, si Liévano fabricó el concepto de libertadura como eufemismo explicativo del uso de la ley por parte de las élites criollas durante la Independencia, negando paradójicamente una verdadera independencia, considero que el fetichismo de la democracia es nuestro mal contemporáneo, un cáncer que es extremadamente dificil de descubrir, puesto que alguien que hable en contra de la democracia hoy podría ser catalogado, ya no en los términos propuestos por Liévano de un "defensor de la arbitrariedad", sino tal vez un fascista criminal apara la izquierda y un autoritario castrochavista para la derecha.

Por lo pronto, continuaré evaluando el contexto para la explicación de este segundo aparte. El fetichismo se ha consolidado en el marco del impulso a la libertad individual, a las identidades, que solicitaba, no solamente una sociedad acallada por el peso de la tradición, sino una economía de mercado dependiente y emergente en nuestro país por allá a principios de los años 1990. Ese fetichismo, tiene como característica, que no se consolidó por conclusión política sino, insisto, por la necesidad de la economía de mercado.

Filósofos tan distintos como Alain Badiou y Fredric Jameson han señalado, a propósito de la actual celebración de la diversidad de estilos de vida, cómo este crecimiento de las diferencias reposa en un subyacente Uno, en la radical obliteración de la diferencia, de la brecha antagonista. (Žižek, 2000, p. 8).

Ese subyacente Uno no es fácil de sustentar en el marco del embrujo, a veces tan absurdo, en que la sociedad colombiana está inserta como producto del velo identitario del fetiche de la democracia y la función benevolente que tiene este último, con las casi perpetuas formas de poder político que existen hoy en Colombia. Por lo pronto, continuaré el desarrollo de la problemática con base en 
una nueva cita: "la "multiplicación" de las diferencias reafirma al subyacente Uno" (Žižek, 2000, p. 8).

¿Quién es ese subyacente "Uno"? Bien, en otra ocasión, en un evento enmarcado en la Semana de la Sociología, un ponente, experto en temas sobre afrodescendientes y en la explicación de todas las luchas identitarias de estas comunidades, estuvo hablando sobre el grave problema de la tierra para las comunidades negras en Colombia. Los argumentos fueron bastante claros, indiscutibles desde ese punto de vista identitario y por supuesto argumentativo. No obstante, cuando pregunté sobre si existía la posibilidad de configurar una visión genérica de un problema social, económico y político como lo es la inequitativa tenencia de la tierra en Colombia y, además, implícitamente en la pregunta le mencioné que dicho problema, probablemente afecta de forma trasversal no solo a los afro sino también a indios y campesinos, entonces recibí un regaño sin opción a réplica enorme, a cuenta de que supuestamente con mi pregunta estaba invalidando y pasando por alto todo el sufrimiento de las personas que fueron traídas desde África, tratadas como animales y sometidas a las más penosas torturas y degradaciones.

En mi mente quedó la pregunta ¿por qué se ofendió tanto ese docente? Pensaba que, si en verdad hubiera querido ofenderlo, tan solo le habría preguntado: ¿Y usted, si es un representante académico que viaja por el mundo hablando del tema afro, por qué no es afro? Eso lo pensé después, pero así lo hubiese pensado allí mismo, por respeto, no me habría atrevido a pronunciarlo. Ahora bien, si yo no quise ofender su discurso, ni mucho menos pasar por alto la esclavización española ¿qué es lo que realmente le ofendió? En el mismo evento, al proponer que dejáramos, por un tiempo, en un segundo plano las reivindicaciones identitarias y pasáramos a confrontar como un Uno solo el poder real que existe en Colombia, una docente que disfrazó su regaño con una pregunta, se salió del recinto antes de poder si acaso explicarle, que 
mi intención no era demeritar las luchas identitarias, sino permitir que sean los módulos organizativos de una sociedad sí y solo sí, como primera cosa, lográramos reconocer que el problema de la segregación, del racismo, de la falta de tierras, de la violencia de género, de la indolencia ecológica, etc., tiene una raíz común, es decir que lo identitario es absolutamente válido, pero posterior al reconocimiento de las causas opresivas que son comunes, que son ese Uno, que Žižek afirma se encuentra subyacente a la diferencia.

Desde otro punto de vista, abordar la lucha identitaria como el eje absoluto de una lucha política constituiría paulatinamente, un propósito concreto en el que un individuo bajo el régimen de una comunidad autoritaria, sea un colectivo, movimiento o secta, pueda perder la noción de la realidad general y con ella, la posibilidad real de transformarla (Touraine, 1997). En otras palabras, hay cada vez más movimientos de lucha política identitaria y eso no es "malo" desde ningún punto de vista, pero así mismo, parece estar más lejos la posibilidad de que la condición común, que por ejemplo oprime o suprime a todos y cada uno por aparte, tenga posibilidades de ser develada. Por consiguiente, probablemente habrá menos tendencia al cambio social... Pero ¿no es un cambio social lo que finalmente se persigue, directa o indirectamente, con una asociación política? Resumo este párrafo con una frase que escuché en una tienda de un barrio bogotano: "Aquí todos sabemos que esto está mal, pero todo el mundo tira para su lado, ni los revoltosos se ponen de acuerdo".

Cuando la diada antagonista es reemplazada por la evidente "creciente multitud", la brecha que se halla así obliterada es, en consecuencia, no solamente la brecha entre el contenido diferente dentro de la sociedad, sino la brecha antagonista entre lo Social y lo no Social, la brecha que afecta la verdadera noción Universal de lo Social. (Žižek, 2001, p. 8) 
Como conclusión de este segundo aparte, el fetiche de la democracia ha tenido relación con el impulso al tema identitario, que poco a poco se ha configurado en el problema identitario. Por supuesto, para muchos colegas y humanistas, lo identitario jamás podría catalogarse como problema; no obstante, cuando se evalúa el fenómeno de la lucha política identitaria y nos encontramos sin resultados más allá de marchas que no devienen en cambios estructurales, foros donde unos van a dormir o a discutir un buen rato y nada más, adjudicación de pequeñas porciones de presupuesto público para hacer eventos conmemorativos, ¡o algo grave en mi opinión! el reciclaje de la cultura política identitaria apropiada por el marketing para que también algunos puedan comprar la desobediencia.

Entonces, es allí, cuando se ven lejos las fórmulas de acción política que produzcan cambios que permitan superar la paradoja planteada inicialmente, es allí cuando la democracia es simplemente un fetiche, más no un modelo político que otorgue posibilidad a los actores sociales de establecer diálogos que permitan el viraje hacia un proyecto político común.

¿Entonces la solución está en negar las identidades? Por supuesto que no, y antes de que el lector comience a enojarse conmigo, quiero ser enfático en esto. Realizar una crítica al problema identitario no es en lo absoluto la negación de las identidades; König (1994) mencionaba que el nacionalismo es un instrumento para la solidaridad, la activación y la movilización políticas de la población, que coloca los intereses de una nación por encima de todos los otros intereses, por supuesto, las luchas identitarias aborrecen al nacionalismo, porque este establece generalidades que niega en ocasiones grandes diferencias. No obstante, si superamos los conceptos de lo nacional, de la identidad, de la democracia, como meros fetiches, y pasamos a comprender nuestros problemas políticos, ese nuestros ¿no constituiría una forma comprensiva genérica que, en vez de ofrecer derivaciones explicativas, podría ofrecer caminos de acción política no paradójicos? 
En tercer lugar, quiero exponer el neologismo planteado en el título de este capítulo. Un neologismo que no es de mi autoría, sino propiamente de Hugo Biagini y Diego Fernández Peychaux. Debo mencionar que me interesan los neologismos, siempre y cuando estos tengan una función suplementaria y no complementaria. Pero ¿por qué neuroliberalismo? Eso suena a neurología y liberalismo. ¿Cómo conectar estos dos megaconceptos en uno solo?

La palabra favorita de la neurología es "déficit", que indica un menoscabo o incapacidad de la función neurológica: pérdida del habla, pérdida del lenguaje, pérdida de la memoria, pérdida de la visión, pérdida de la destreza, pérdida de la identidad y un millar de carencias y pérdidas de funciones (o facultades) específicas. (Sacks, 1987, p. 9)

Definitivamente esta implicación de "déficit" para entender la neurología que señala Oliver Sacks, me parece adecuada en relación con la participación en la conformación del concepto neuroliberalismo. A propósito del mismo, prefiero que Biagini exponga su razón de ser.

Me valí del mismo concepto cuando tuve ocasión de salirle al ruedo a la tan sonada inauguración por Vargas Llosa de la Feria Internacional del Libro, celebrada en Buenos Aires un par de años atrás. Allí, el frustrado candidato a la presidencia de su país no solo argumentó banalmente contra el populismo y el peronismo, como manifestaciones autoritarias, sino que también procuró eximir de ese cargo a la problemática tradición liberal en términos muy falaces: "el liberalismo -sostuvo- no tiene nada que ver con las dictaduras”. (Biagini \& Fernández, 2015, p. 115)

De acuerdo con lo anterior, podría aludirse que el motivo de la búsqueda conceptual de Biagini y Fernández está estrechamente relacionado con los términos falaces con los que se asume la connotación, en el ejemplo anterior, de un contexto histórico tan grave 
y complejo como lo fueron las dictaduras. ¿Por qué a Vargas Llosa, al igual que muchos fundamentalistas, le cuesta tanto hacer la relación entre liberalismo y opresión o liberalismo y dictaduras? Mi respuesta rápida: son fetichistas del liberalismo. Mi respuesta más comprensiva, rondaría en los aspectos en que una ideología, preconiza a un súper yo, como condición necesaria para la eliminación del elemento colectivo, en últimas, una forma en que un individuo se autoconvence de que el mundo es solo el mundo en el que ha crecido, que el mundo es solo él, nada más que él, así en el fondo sepa que sin los demás y sin lo colectivo está perdido.

Fotografía 2. El dictador Augusto Pinochet en reunión privada con Milton Friedman

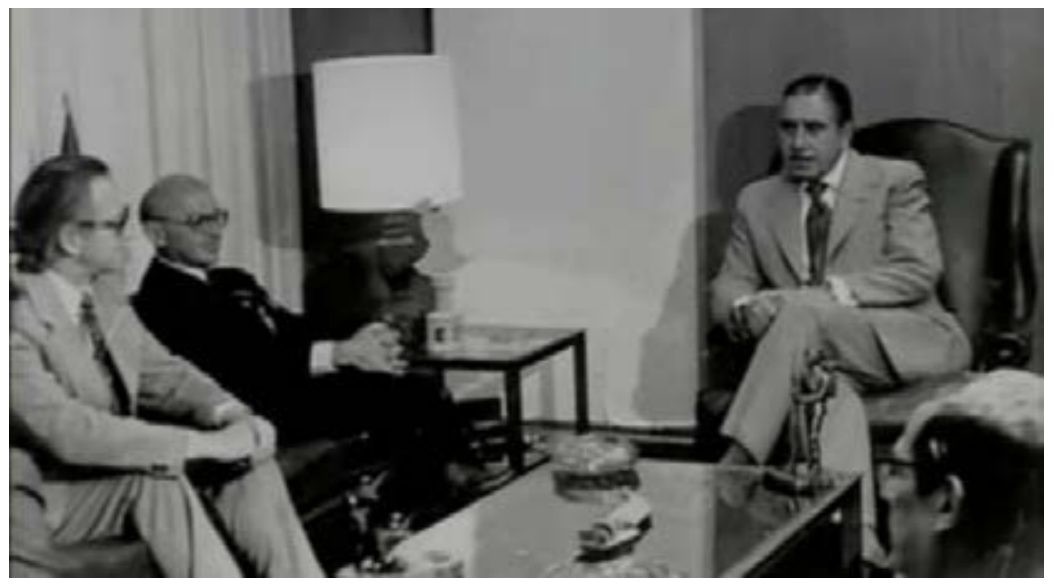

Fuente: tomado de https://lavozdebida.files.wordpress.com/2013/06/ friedmanpinochet.jpg

La respuesta no es fácil de diseñar, pero no se puede hablar de neuroliberalismo sin reconocer el ámbito ideológico-económico y contemporáneo que hoy domina el mundo. Hablar de la ideología económica y política que hoy domina el mundo significaría dedicar un capítulo entero a Milton Friedman y su batallón de liberales. A propósito de lo anterior y como un dato importante 
por tener en cuenta, hoy sus discípulos son llamados neoliberales y algunos fundamentalistas "reencauchadores" de la escuela austriaca o neomisioneros de Murray Rothbard se han autodenominado "libertarios" y andan convenciendo incautos por Bogotá, ignorando, o tal vez pisoteando por completo todo el fundamento teórico-conceptual del anarquismo, sin advertir que aquí en Colombia el concepto libertario no es para nada nuevo y tiene raíces ostensiblemente diferentes.

En definitiva, tocaré tan solo el aspecto, a mi juicio, más elemental de la teoría de Friedman y posteriormente continuaré el desglose de este tercer aparte.

La preservación de la libertad requiere la eliminación de esa concentración de poder en la mayor medida posible y la dispersión y distribución de cualquier poder que no pueda eliminarse, un sistema de checks and balances. Al sustraer la organización de la actividad económica del control de la autoridad política, el mercado elimina esta fuente de poder coercitivo. Le permite al poder económico ser un balance contra el poder político en vez de un refuerzo. (Friedman, 1979, p. 7)

Frente a lo anterior, el problema es que, si el poder coercitivo del Estado es eliminado por el mercado, pero el poder económico se toma el poder político excluyendo al Estado, entonces la única instancia colectiva de poder (el Estado) queda anulada y por supuesto bajo el control del poder económico que según la teoría vendría a ser el mercado.

No obstante, el mercado no es un sujeto. El mercado es un escenario simbólico y manifiesto de intercambios, intercambios que realizan sujetos de carne y hueso. Por lo tanto, dicho mercado, al igual que el Estado, pronto termina dominado por un poder, en este caso, ya no un poder público-colectivo, sino privado-individual, que solicita la desregularización estatal no para poder ejercer su libertad, sino para ejercer poder coercitivo individual sobre 
la colectividad en nombre de la libertad y con sustento en el poder económico... Claramente lo que ocurre hoy. ¿'Tiene dudas? Piense en Trump.

El neuroliberalismo entonces es esa "apuesta por el egoísmo virtuoso que entroniza el yo como pasaporte al bienestar, mientras se estima que la palabra nosotros $3 / 4$ equivalente a servidumbre, miseria y falsedad $3 / 4$ designa la raíz de todos los males" (Biagini \& Fernández, 2015, p. 117). Esa raíz de todos los males, en relación con los planteamientos de Friedman, es efectivamente el Estado y, por consiguiente, el nuevo dios a venerar es el mercado. "Esta aparente juventud de las posiciones mercadófilas nos llevó a preguntarnos cuáles son sus bases operacionales" (Biagini \& Fernández, 2015, p. 119). Si el mercado también se constituye en otra especie de fetiche, entonces deben existir ciertas tendencias implícitas en los sujetos. Los sujetos del neuroliberalismo.

Los sujetos del neuroliberalismo huyen hacia la realidad estructurada fantásticamente, porque no soportan seguir soñando, es decir, presentarse frente a su real deseo no incorporado al sistema del mercado. Esa imposibilidad traumática requiere suspender el sueño y buscar refugio en una fantasía de resultado igualmente insoportable, pero significada a través de los vítores al exitoso. (Biagini \& Fernández, 2015, p. 118)

El neuroliberalismo es lo más parecido a una programación neurolingüística, pero con implicaciones directas sobre una realidad que pesa y que no se quiere soportar, que se quiere evadir con la construcción de las fantasías. ¿Para qué construir fantasías en nuestra realidad social? Indudablemente para evitar el peso de la realidad misma. ¿Se podría decir que funciona como una droga? No específicamente, puesto que una droga es un agente exógeno; no obstante, la conclusión de un individuo que por ejemplo prefiere tener dos carros a crédito, cinco vestidos a crédito, no tener víveres o muebles en casa, pero alardear frente a los demás o humillar a 
los que no poseen sus artefactos, es un comportamiento producto de una conclusión endógena.

Por lo tanto, el neuroliberalismo es un fenómeno que existe como resultado de la ideología económica y política liberal que propone al mercado como regulador de la vida humana. Ahora bien, de acuerdo con las falencias señaladas en el planteamiento más elemental de Friedman, finalmente no sería descabellado afirmar que unos pocos individuos han logrado instituir sobre amplios sectores de la sociedad el neuroliberalismo como un deber ser de la vida humana actualmente.

Lo fantástico se ubica, por lo tanto, en la "relación con" y no en la realidad misma. Es decir, que los sujetos del neuroliberalismo brindan realidad a la ficción que conocen, evitando construir un drama de la represión en cual la viven. Al focalizar el análisis en dicha relación con la realidad, se aprecia el ambivalente proceso de sujeción en el que aceptan las premisas fundacionales del neoliberalismo: la virtud del egoísmo y la fetichización del exitoso. (Biagini \& Fernández, 2015, p. 118)

En resumen, como una condición básica para hablar de política en Colombia, emerge la necesidad de saber no solo acerca de filosofía política o historia de la humanidad, sino que hace falta aún, el reconocimiento de qué o cuál es entonces aquella ideología que está llenando el vacío existente. ¿Cuál vacío? El de una sociedad que pierde de vista a pasos acelerados la importancia de la política, y que ha cambiado el esfuerzo por comprender, por el consumo de información, que le detalla con excelentes artículos mediáticos el desastre que sigue aprobando con una actitud desinteresada o indiferente frente a la política.

El lector podría concluir conmigo que estamos frente a la necesidad de un desenmascaramiento, pues "ya no la libertad, sino las categorías sociales de éxito/fracaso son las que determinan el horizonte global del campo ideológico" (Biagini \& Fernández, 2015, 
p. 119). Esto podría desatar el problema que algunas personas tienen para desarrollar críticas a emblemáticos personajes contemporáneos que son exponentes y figuras públicas del liberalismo.

Alguna vez, alguien me preguntaba “¿cómo desarrollar una crítica al liberalismo, si cuando lees sus planteamientos, no sabes cómo hablar mal de alguien que defiende un valor como la libertad?". Muy bien, la punta del iceberg del fracaso teórico liberal, se halla implícita en la ingenuidad de Friedman al plantear que por ejemplo los intercambios en el mercado continuarán siendo producto de la cooperación voluntaria (Friedman, 1979) y perpetuos en el tiempo o que el mercado está exento de ser absorbido por el poder económico.

Está comprobado que el mercado como escenario natural de las relaciones sociales de la humanidad es dominado bien sea por los Estados de tipo socialista o es dominado por una pequeña plutocracia en los Estados de tipo capitalista, dejando siempre al grueso de los sujetos sometidos bajo reglas que paulatinamente ya no son naturales o que tampoco son producto de la acción de "la mano invisible", pues creo que con la crisis de 2008 y la ley de salvamento estadounidense que tomó dineros públicos (como toda una ley socialista) para salvar los bancos, quedó claro que si los postulados económicos de Marx fracasaron en la práctica, también han fracasado los de Friedman y Smith.

Pero bueno, teóricamente se puede dar una gran batalla, de hecho, miles de intelectuales alrededor del mundo la dan, ¿pero y la vida cotidiana? ¿Cómo comprender a esa mayoría que no le interesa el debate político, que no le interesa el debate teórico y que se comporta de la forma más individualista posible como producto de la inducción exógena del neuroliberalismo que produce la conclusión endógena de comportarse de una forma absolutamente egoísta? La identificación del neuroliberalismo es un paso inicial, además, en una sociedad capturada por el neuroliberalismo la realidad objetiva que intenta plantear la crítica que por ejemplo 
desarrolla el humanismo se vuelve invisible porque supuestamente los significantes de los que depende esa realidad se han vuelto ilusiones vacías.

No obstante, y considero que aquí puede estar la puerta de entrada a la comprensión de la validez de la reflexión crítica, es que finalmente, incluso el sujeto exitoso culmina ocupando una posición apenas distinta en la misma cadena de sometimiento y dominio que los individuos fracasados (Biagini \& Fernández, 2015). 



\section{Capítulo VII \\ Del individuo al sujeto crítico, y luego, al sujeto político}

$\mathrm{D}$ esde que comencé mis estudios en sociología, siempre que leía los textos, me preguntaba a medida que se acercaba el final, ¿con qué propuesta saldrá este autor?, siempre al final de un libro, como lectores, ¡y más como interesados en la política! buscamos que luego de las críticas, aparezcan las propuestas, pues de una manera casi crónica, la crítica política es traducida en "criticadera" por muchos lectores, a mi juicio, por la falta de propuestas de los autores.

¿Qué se puede promover? ¿El cambio del mundo? Que todos los estudiantes y docentes ¿sean los próximos protagonistas de la historia mundial? La verdad, al igual que un reconocido anarquista llamado Buenaventura Durruti, estoy convencido de que si el corazón de alguien es transformado por la utopía, entonces el mundo está cambiando en ese preciso instante. De la misma manera, estoy convencido, como menciona el Papa Francisco, que la constante acumulación de posibilidades para consumir distrae el corazón e impide valorar cada cosa y cada momento (Papa Francisco, 2015) iy es precisamente en la valoración de cada cosa y de cada momento, donde se halla la oportunidad de reflexionar desde el humanismo! 